\title{
Trends in opioid use following balloon kyphoplasty or vertebroplasty for the treatment of vertebral compression fractures
}

\author{
W. $\mathrm{Ni}^{1} \cdot$ C. Ricker ${ }^{1} \cdot$ M. Quinn ${ }^{1} \cdot$ N. Gasquet ${ }^{1} \cdot$ D. Janardhanan ${ }^{2} \cdot$ C.J. Gilligan ${ }^{2} \cdot$ J.A. Hirsch ${ }^{3}$ (I)
}

Received: 1 March 2021 / Accepted: 18 September 2021 / Published online: 2 November 2021

(c) The Author(s) 2021

\begin{abstract}
Summary This retrospective analysis of insurance claims evaluated real-world trends in prescription fills among patients treated with balloon kyphoplasty $(N=6,656)$ or vertebroplasty $(N=2,189)$ following diagnosis of vertebral compression fracture. Among those with evidence of opioid use, nearly half of patients discontinued or reduced prescription fills relative to pre-operative levels.

Introduction Vertebral compression fractures (VCF) are associated with debilitating pain, spinal misalignment, increased mortality, and increased healthcare-resource utilization in elderly patients. This study evaluated the effect of balloon kyphoplasty (BKP) or vertebroplasty (VP) on post-procedure opioid prescription fills and payer costs in patients with VCF.

Methods This was a retrospective analysis of a large, nationally representative insurance-claims database. Clinical characteristics, opioid prescription patterns, and payer costs for subjects who underwent either BKP or VP to treat VCF were evaluated beginning 6 months prior to surgery through 7-month follow-up that included a 30-day, postoperative medication washout. Patient demographics, changes in opioid utilization, and payer costs were analyzed.

Results A total of 8,845 patients met eligibility criteria (75.3\% BKP and $24.7 \%$ VP) with a mean of age 77 and $74 \%$ female. Among the $75 \%$ of patients who used opioids, $48.7 \%$ of patients discontinued opioid medication and $8.4 \%$ reduced prescription fills versus preoperative baseline. Patients who reduced or discontinued prescriptions exhibited a decrease in all-cause payer costs relative to pre-intervention levels, which was a significantly greater change relative to patients with no change, increase, or new start of opioids.

Conclusions Interventional treatment for VCF was associated with decreased or discontinued opioid prescription fills and reduced payer costs in follow-up in a significant proportion of the study population. Reduction of opioid-based harms may represent a previously unrecognized benefit of vertebral augmentation for VCF, especially in this elderly and medically fragile population.
\end{abstract}

Keywords Balloon kyphoplasty $\cdot$ Vertebroplasty $\cdot$ Vertebral compression fractures $\cdot$ Opioids

\begin{tabular}{|c|c|c|c|c|}
\hline \multicolumn{2}{|c|}{ Abbreviations } & \multirow{4}{*}{$\begin{array}{l}\text { Balloon kyphoplasty } \\
\text { Charlson Comorbidity Index } \\
\text { Conservative medical } \\
\text { management }\end{array}$} & \multirow{4}{*}{$\begin{array}{l}\text { CPT } \\
\text { ICD-9-CM and ICD-10-CM }\end{array}$} & \multirow{4}{*}{$\begin{array}{l}\text { Current Procedural } \\
\text { Terminology } \\
\text { International classification of } \\
\text { diseases clinical modification }\end{array}$} \\
\hline \multirow{3}{*}{\multicolumn{2}{|c|}{$\begin{array}{l}\text { BKP } \\
\text { CCI } \\
\text { CMM }\end{array}$}} & & & \\
\hline & & & & \\
\hline & & & & \\
\hline $\begin{array}{l}\text { J.A. Hirsch } \\
\text { jahirsch@mgh.harvard.edu }\end{array}$ & \multicolumn{2}{|l|}{$\begin{array}{l}\text { J.A. Hirsch } \\
\text { jahirsch@mgh.harvard.edu }\end{array}$} & $\begin{array}{l}\text { MME } \\
\text { VCF }\end{array}$ & $\begin{array}{l}\text { Morphine milligram } \\
\text { equivalents } \\
\text { Vertebral compression } \\
\text { fractures }\end{array}$ \\
\hline 1 & \multicolumn{2}{|c|}{$\begin{array}{l}\text { Health Economics \& Outcomes Research, Medtronic Plc., } \\
710 \text { Medtronic Parkway, Minneapolis, MN 55432, USA }\end{array}$} & VP & Vertebroplasty \\
\hline 2 & \multicolumn{4}{|c|}{$\begin{array}{l}\text { Department of Anesthesiology, Perioperative and Pain } \\
\text { Medicine Brigham \& Women's Hospital, Boston, USA }\end{array}$} \\
\hline 3 & \multicolumn{4}{|c|}{$\begin{array}{l}\text { Interventional Neuroradiology, Massachusetts General } \\
\text { Hospital and Harvard Medical School, Boston, MA 02114, } \\
\text { USA }\end{array}$} \\
\hline
\end{tabular}




\section{Introduction}

An estimated 1.5 million vertebral compression fractures (VCF) occur in the USA every year [1]. Whether as a result of osteoporosis or metastatic disease within the vertebral column, VCFs may cause disabling pain and can precipitate a progressive cascade of deformity, disability, and mortality that, in addition to the quality of life detriment, also place enormous burden on healthcare resources [2-6].

Treatment approaches for VCF include conservative medical management (CMM), consisting of analgesia, bracing, bed rest, and physical therapy or percutaneous image-guided vertebral augmentation procedures such as balloon kyphoplasty (BKP) and vertebroplasty (VP). Because VCF patients are typically elderly and medically fragile, the tradeoffs between CMM and interventional approaches are not necessarily straightforward. For example, while evidence has suggested that vertebral augmentation procedures are effective in improving patient-reported pain, quality of life, and resource utilization compared to CMM [7-15], interventional treatment is not without with its own set of risks and incremental costs [16, 17]. Therefore, evidence from a broader set of outcome measures would be useful to better inform the risk-benefit analysis for these patients.

One important yet infrequently collected outcome measure in this population is patient utilization of opioid analgesics for VCF-associated pain. VCF patients treated with CMM are often prescribed a short-term regimen to treat pain during the acute VCF episode, followed by a low maintenance dose as needed to manage ongoing pain [18-21]. By way of comparison, patients with chronic back pain or cancer pain are sometimes prescribed many times that amount-as much as 90 daily morphine milligram equivalents (MME) or more as their duration of pain progresses $[22,23]$. Because opioid regimens less than 20 MME daily are associated with much lower risk of opioid overdose [22], the contrast may explain why opioid utilization after VCF has not garnered significant attention as an outcome of interest. Nevertheless, even low-dose opioid use is associated with negative outcomes in elderly populations [24-28], and therefore it is of interest to know whether interventional treatments like BKP and VP can mitigate not just pain itself, but also opioid use in VCF patients. As a measure that can serve as a proxy not just for pain relief but also for opioid-associated morbidity, a study of patterns of opioid utilization before and after vertebral augmentation may provide insights to inform risk and benefit assessments of interventional treatment versus CMM.

To our knowledge, the effect of interventional treatments for VCF on opioid utilization patterns has not been formally investigated as a primary outcome. The present study was designed to evaluate how patterns in opioid utilization change among VCF patients after treatment with $\mathrm{BKP}$ or VP.

\section{Methods}

\section{Data source}

The source of data for this retrospective analysis was the IBM MarketScan ${ }^{\circledR}$ research database, 2008-2018 (IBM Watson Health, Armonk, New York). This database contains de-identified encounter information, inpatient and outpatient medical and pharmacy claims, demographic data, and health-plan enrollment information from more than 135 million patients covered by commercial or Medicare Advantage insurance.

\section{Ethics statement}

The database is a de-identified, HIPAA compliant, closed system of administrative claims. Therefore, this study did not require approval by an Institutional Review Board.

\section{Patient selection}

All codes used for patient selection and data collection are summarized in Appendix 1 Table 4. These include International Statistical Classification of Diseases (ICD-9-CM and ICD-10-CM) diagnosis and procedure codes, Current Procedural Terminology (CPT) procedure codes, and medication National Drug Codes (NDC).

All patients age 18 or older with a diagnosis code for pathologic VCF (i.e., non-traumatic) and a procedure code for either BKP or VP were identified, within a timeframe that allowed for a 6-month pre-surgical baseline and maximum 7-month follow-up for all patients. Patients were required to have continuous health-plan enrollment during the 12-month period before the index date. Continuous health-plan enrollment was not required during the followup period due to the elevated risk of death in this patient population [7, 29], with follow-up ending at the earlier of either health plan disenrollment or 7 months post-procedure, whichever occurred first. Date of death was not available in this dataset; therefore, we assumed that in this elderly population, disenrollment was likely due to death and, consequently, end of follow-up at time of disenrollment.

Patients were excluded from analysis if they underwent both a BKP and a VP procedure during the initial (index) procedure visit, or if they had subsequent BKP or VP procedure(s) performed during follow-up. Because total healthcare utilization for pain management in the setting of 
cancer is high [30, 31], VCF patients with any diagnosis of active cancer, defined as one inpatient or two outpatient visits with a diagnosis code for cancer at any time during the study period, were also excluded.

To increase the likelihood that opioids prescribed were related to the acute VCF event, rather than for management of unrelated, chronic condition(s), patients with one or more opioid prescription fills during the 6 months prior to the baseline period (i.e., months 12 to 7 prior to intervention) were excluded from analyses. Additionally, those with formal diagnosis of opioid use disorder or opioid dependence at any point in the year prior to intervention were excluded.

Despite attempts to include a matched CMM comparator cohort by applying propensity-score matching models, opioid prescription fills at baseline remained higher in the intervention cohorts relative to CMM, potentially because patient perception of pain intensity was not available within the administrative claims data. Therefore, we included a 6-month baseline, with data collected prior to surgical intervention, which provided an internal means of comparison.

\section{Study period}

For each patient, the index date for analysis was defined as the admission date for the visit during which a BKP or VP procedure was performed (Supplemental Figure S1). The baseline period was defined as the 6 months through 1 day prior to the index date. A 1-month washout period was applied from the date of the index procedure through 1 month after discharge in order to exclude opioid prescriptions related to post-surgical pain from the procedure itself, but not from the VCF event. The post-washout follow-up time period was defined as months 1 to 7 after surgical discharge, with this time period used for opioid and cost-related study measures.

\section{Study measures}

\section{Patient demographics and baseline clinical characteristics}

Patient age, sex, and geographic region were summarized. Clinical characteristics included the Charlson Comorbidity Index (CCI) score [32] and history of specific comorbidities (osteopenia, osteoporosis, chronic pain) at baseline. Because specific date of fracture was not available, the date of first observed diagnosis of VCF in claims data was used as a proxy. The number of days from first diagnosis to procedure admission date was summarized.

\section{Characterization of daily opioids prescribed}

Because the available data could not be used to determine actual consumption of prescribed opioids, prescription fills were used as a surrogate measure for opioid utilization. Number of days treated with prescription opioids was calculated from pharmacy claims that included the prescription NDC, strength, units, and days' supply. In the scenario of overlapping days' supply from multiple prescriptions, the treated day was counted once. Average daily opioids prescribed were expressed in MMEs using published CDC conversion factors for converting opioid medication strengths to oral MME (Appendix 2 Table 5).

In order to facilitate a more granular analysis of opioid utilization, patients were assigned to four, mutually exclusive categories that were stratified according to level of daily MME based upon a patients' prescriptions: none (no opioid prescriptions filled), low ( $<2 \mathrm{mg} /$ day), moderate ( 2 to $<7$ $\mathrm{mg} /$ day), and high ( $\geq 7 \mathrm{mg} /$ day). This stratification scheme was developed based on a combination of authors' clinical experience with typical dosing for patients with acute VCFrelated pain and the distribution of MME in prescription fills observed in the study population.

Average daily MME in patient prescription fills and the number of opioid treatment days were summarized at 2-month intervals both in the baseline and post-washout follow-up periods. These intervals were selected to reduce the effect of monthly fluctuations due to overlapping prescription fills or gaps between fills. Results were also stratified by opioid prescription category.

\section{Opioid utilization trends}

The effect of surgical intervention on levels of daily opioids prescribed was characterized by comparing patients' prescription category in baseline against their opioid prescription category after the index procedure admission and washout period. Changes in prescription category were then analyzed according to the opioid utilization trends defined in Table 1.

To determine the potential impact of the 1-month washout period on the results, a sensitivity analysis was performed in which the change in opioid utilization trend was calculated based on data from the 6 months immediately following the discharge date of the index admission.

\section{Logistic regression analysis of baseline characteristics}

Baseline demographic and clinical characteristics were analyzed in a logistic regression model to determine if any of the factors were significantly associated with reduction or discontinuation of opioid prescription fills after a BKP or VP procedure. Covariates analyzed were age, sex, census region, CCI score, history of diagnosed osteopenia or osteoporosis, opioid overdose, and presence of baseline non-opioid medication use (muscle relaxants or anticonvulsants). 
Table 1 Opioid prescription trend definitions

\begin{tabular}{ll}
\hline Trend (change from baseline to follow-up) & Definition \\
\hline Increased & Changed from a lower opioid prescription category to a higher opioid prescription category \\
Decreased & Changed from a higher opioid prescription category to a lower opioid prescription category \\
Discontinued & Changed from any opioid prescription category to "none"; i.e., no opioid prescription fill \\
present in post-washout follow-up & Changed from "none" to any opioid prescription category \\
New start & No change in opioid prescription category \\
Same & No opioid prescription fill at any point during study period \\
Never &
\end{tabular}

\section{Payer costs, baseline versus follow-up}

Generalized linear models were applied to evaluate the adjusted impact of opioid utilization trends (i.e., changes in opioid prescription category) after BKP and VP procedures on all-cause healthcare costs, controlling for age, gender, census region, CCI score, history of diagnosed osteopenia or osteoporosis, and prescription fills for non-opioid medications (muscle relaxants and anticonvulsants). Models were calculated with a Gaussian distribution and identity link function.

\section{Statistical analyses}

Sample selection, creation of analytic variables, significance testing, and regression analyses were performed using the Instant Health Data (IHD) platform (Panalgo, Boston, MA) and R software version 3.2.1 (R Foundation for Statistical Computing, Vienna, Austria). Mean, median, and standard deviation (SD) were used to summarize continuous measures and proportions to summarize categories. Statistical significance testing across patient subgroups was tested by one-way ANOVA for continuous variables and Pearson's Chi-squared test for categorical variables. When baseline and follow-up opioid prescription categories were compared, the paired $t$ test was used for continuous variables and McNemar's Chi-square test was used for categorical variables.

\section{Results}

\section{Demographic and clinical characteristics}

After all inclusion and exclusion criteria were applied, 8,845 patients were available for analysis. Of those, $75.3 \%$ underwent BKP and $24.7 \%$ underwent VP (Supplemental Figure S2). All index procedures took place between 1/1/2009 and $04 / 30 / 2018$.

Patient demographics and baseline characteristics, stratified by opioid prescription category, are summarized in
Table 2. Overall, mean \pm SD age of patients in this study was $77 \pm 12$, with the majority female $(73.8 \%)$. Prevalence of muscle relaxant prescription fills slightly decreased from baseline (23.4\%) to follow-up (22.0\%), $P=.0016$, while prevalence of a muscle relaxant prescription fill showed a larger decline from baseline (24.9\%) to follow-up (9.3\%), $P<.001$.

During the baseline period, older patients (age $\geq 65$ ) were more likely belong to the "none" or "low" opioid prescription-fill categories, while younger patients were more likely to be identified as filling prescriptions for opioids at higher levels (Table 2). Comorbidity burden, as measured by the CCI score, was significantly different among the four opioid prescription categories ( $p$ value $<0.0001$ ). Patients with one or more comorbidities were more likely to be prescribed opioids during the baseline period than patients with no comorbidities. A higher proportion of patients in the moderate and high-prescription categories had a history of diagnosed osteopenia or osteoporosis, or a chronic pain disorder. "Moderate" and "high" levels of opioid prescriptions filled were associated with longer median times from first VCF diagnosis to surgical treatment compared to "none" or "low" opioid prescriptions filled (Table 2).

\section{Opioid prescription fills before and after vertebral augmentation procedures}

During the study, $25.0 \%$ of vertebral augmentation patients showed no evidence of any opioid prescription fill at any time in baseline or follow-up. These patients were by definition excluded from analyses of prescription-fill trends in Figs. 1 and 2 and the logistic regression analysis shown in Table 3.

The overall median (interquartile range; IQR) number of baseline opioid prescription treated days was 15 (IQR: 7-30). During the post-washout, follow-up period, the overall median (IQR) number of treated days that subjects were prescribed opioids was 30 (IQR: 10-64). Overall median (IQR) daily MME prescribed during baseline was $2.4 \mathrm{mg} /$ day (1.0-5.3). During the post-washout, follow-up period, 
Table 2 Demographics and baseline clinical characteristics*

\begin{tabular}{|c|c|c|c|c|c|c|}
\hline \multirow[b]{3}{*}{ Sample size, $N$} & \multirow{3}{*}{$\begin{array}{l}\text { Overall } \\
8,845\end{array}$} & \multicolumn{4}{|c|}{ Baseline opioid consumption category } & \multirow[b]{2}{*}{$p$ value } \\
\hline & & None & Low & Moderate & High & \\
\hline & & 2,941 & 2,581 & 2,263 & 1,060 & \\
\hline \multicolumn{7}{|l|}{ Age, y } \\
\hline Mean & 77 & 78.1 & 78.1 & 75.9 & 73.3 & \multirow[t]{3}{*}{$<0.0001$} \\
\hline SD & 12 & 12.4 & 11.4 & 11.5 & 12.3 & \\
\hline Age group, $\%$ & 80 & 81 & 81 & 78 & 76 & \\
\hline $18-64$ y & $18.5 \%$ & $17.4 \%$ & $15.0 \%$ & $19.9 \%$ & $26.9 \%$ & \multirow[t]{2}{*}{$<0.0001$} \\
\hline$\geq 65 \mathrm{y}$ & $81.5 \%$ & $82.6 \%$ & $85.0 \%$ & $80.1 \%$ & $73.1 \%$ & \\
\hline Female, $\%$ & $73.8 \%$ & $73.5 \%$ & $75.0 \%$ & $74.5 \%$ & $70.4 \%$ & 0.0231 \\
\hline \multicolumn{7}{|l|}{ Region, $\%$} \\
\hline Northeast & $11.8 \%$ & $12.4 \%$ & $10.6 \%$ & $11.3 \%$ & $14.2 \%$ & \multirow[t]{5}{*}{0.0001} \\
\hline South & $37.4 \%$ & $35.1 \%$ & $40.0 \%$ & $37.2 \%$ & $38.3 \%$ & \\
\hline West & $11.7 \%$ & $10.9 \%$ & $11.7 \%$ & $11.6 \%$ & $14.2 \%$ & \\
\hline Midwest & $38.0 \%$ & $40.8 \%$ & $36.7 \%$ & $38.4 \%$ & $32.5 \%$ & \\
\hline Missing & $1.1 \%$ & $0.8 \%$ & $1.0 \%$ & $1.5 \%$ & $0.9 \%$ & \\
\hline \multicolumn{7}{|l|}{ CCI score, $\%$} \\
\hline 0 & $58.6 \%$ & $62.5 \%$ & $59.9 \%$ & $54.9 \%$ & $52.1 \%$ & \multirow[t]{3}{*}{$<0.0001$} \\
\hline 1 & $20.3 \%$ & $17.7 \%$ & $20.1 \%$ & $22.9 \%$ & $22.5 \%$ & \\
\hline$\geq 2$ & $21.1 \%$ & $19.8 \%$ & $20.0 \%$ & $22.1 \%$ & $25.5 \%$ & \\
\hline \multicolumn{7}{|l|}{ Baseline diagnoses, $\%$} \\
\hline Osteopenia & $11.9 \%$ & $8.6 \%$ & $11.4 \%$ & $14.6 \%$ & $16.4 \%$ & $<0.0001$ \\
\hline Osteoporosis & $30.7 \%$ & $22.6 \%$ & $30.1 \%$ & $36.9 \%$ & $41.4 \%$ & $<0.0001$ \\
\hline Chronic pain disorder & $4.1 \%$ & $2.6 \%$ & $3.5 \%$ & $4.7 \%$ & $8.4 \%$ & $<0.0001$ \\
\hline \multicolumn{7}{|c|}{ Time from first observed VCF diagnosis to index surgery admission, days } \\
\hline Mean & 22.2 & 17.7 & 17.1 & 25.9 & 39.2 & \multirow[t]{4}{*}{$<0.0001$} \\
\hline SD & 43.6 & 48.2 & 36.6 & 41.2 & 46.1 & \\
\hline Median & 7.0 & 1 & 6 & 13 & 22.5 & \\
\hline IQR & $1-23$ & $1-12$ & $1-16$ & $3-29$ & $7-55.3$ & \\
\hline
\end{tabular}

Source: MDT Truven CCAE/MDCR 2008-2018

NOTE: Stratifications to define historic opioid use: (A) $(0<\mathrm{X}<2 \mathrm{mg} / \mathrm{day})$, moderate $(2 \leq \mathrm{X}<7 \mathrm{mg}$ / day), high ( $X \geq 7 \mathrm{mg} /$ day)

* $P$ value calculated across baseline opioid use categories: Pearson's Chi-square test for categorical measures and one-way ANOVA for continuous measures overall median daily MME prescribed was $4.1 \mathrm{mg} /$ day (IQR: 1.6-9.7).

The distribution of patients among each of the four opioid prescription categories before and after vertebral augmentation and the differences in distribution between baseline and the post-washout period are shown in Fig. 1.

\section{Trends in opioid prescription fills after vertebral augmentation}

When evaluating specific opioid utilization trends, $57.1 \%$ of patients with any baseline opioid use decreased or discontinued opioid prescription fills post-washout follow-up (Fig. 2). Some patients experienced an increase in opioid prescription fills after vertebral augmentation (13.9\%) or newly started an opioid prescription (10.9\%) in follow-up (Fig. 2).
The average number of treated days within each 2-month time window prior to and following intervention is depicted in Fig. 2A. Among the 48.7\% who discontinued opioid prescription fills, the average number of treated days in the 2 months prior to surgery was 22.1 days versus 9.7 in the 2 months post-washout. Trends in average daily MME were similarly analyzed in 2-month intervals (Fig. 2B). Opioid daily dose increased during the baseline period, peaking in the 2 -month period before the index procedure, which by definition included the initial VCF fracture event for the majority of patients (average time from diagnosis to surgery of 23 days). Among those who discontinued opioid prescription fills in follow-up, the average daily MME in the two months prior to surgery was $7.2 \mathrm{mg} / \mathrm{day}$, decreasing to zero in follow-up (by definition of discontinuation). 
Fig. 1 Patient distribution among opioid prescription* categories before and after vertebral augmentation procedures (balloon kyphoplasty or vertebroplasty) and absolute change from baseline. *Opioid prescription fills during the washout period was excluded from analysis. Subjects with no evidence of opioid prescription fills during any phase of the study were also excluded. Opioid prescription categories, expressed in daily MME: none, low $(<2 \mathrm{mg}$ /day), moderate $(2$ to $<7 \mathrm{mg} /$ day), and high ( $\geq 7$ $\mathrm{mg} /$ day)

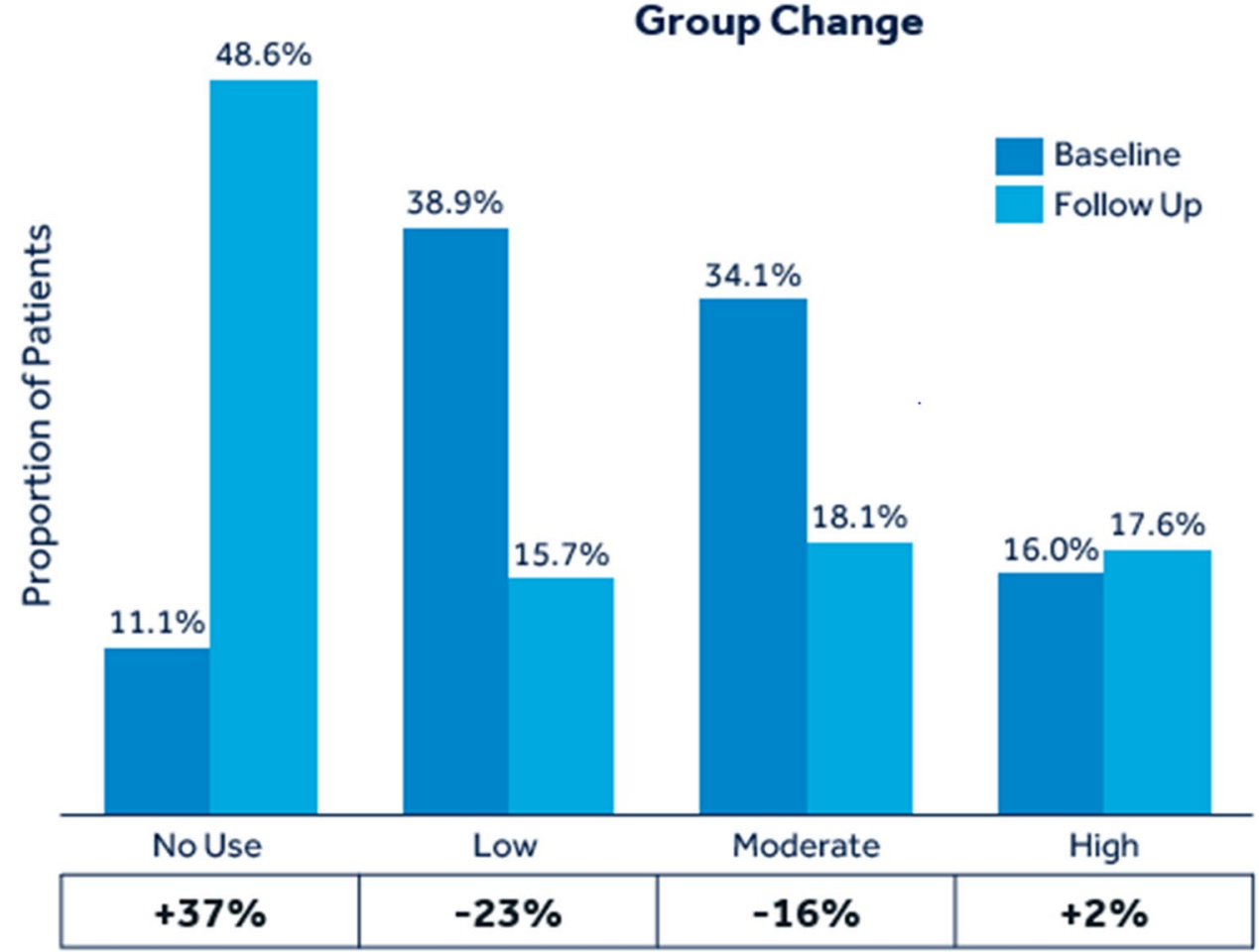

A sensitivity analysis was performed to test the robustness of the opioid status change in the absence of applying the 1-month post-surgical washout period. When opioid prescription-fill data from the 30 days immediately following vertebral augmentation were included in the analysis, the proportion of patients categorized to the "increased," "new start," "same," "decreased," "discontinued," or "same" opioid groups varied from $-1.8 \%$ to $+0.7 \%$ vs. the core analysis including a 1-month washout.

A second sensitivity analysis was completed to test the affect of including all years available in the data source (2008-2018) used in our main analysis versus only more recent years (2015-2018). Overall, the proportion of patients categorized into each opioid use group changed minimally, ranging from $-2.3 \%$ to $+1.0 \%$ different across the two time periods.

\section{Covariates associated with trends in opioid prescription fills}

A multivariate logistic regression analysis was performed to identify factors associated with changes in opioid prescription fills after vertebral augmentation procedures (Table 3). Factors associated with decreased or discontinued opioid prescription fills after vertebral augmentation were older age (65 or older), baseline diagnosis of osteoporosis, and baseline use of muscle relaxants. Conversely, presence of more comorbidities, as measured by higher CCI score, was associated with increased opioid prescription fills after vertebral augmentation.

\section{Association between trends in opioid prescription fills and all-cause payer costs}

Average all-cause payer costs, adjusted for patient demographic and clinical factors, were compared between the baseline and follow-up periods (Fig. 3). Patients who underwent vertebral augmentation and who maintained, increased, or started new opioid prescription fills after the procedure incurred greater average all-cause payer costs in the followup period than in baseline $(+\$ 160)$, whereas patients who decreased or discontinued opioid prescription fills incurred significantly reduced average all-cause payer costs compared to baseline $(-\$ 6,759 ; P<.0001$ across opioid utilization groups).

\section{Discussion}

This retrospective analysis of commercial-claims data evaluated the effect of vertebral augmentation (either BKP or VP) on fills of opioid prescriptions-as a surrogate measure for opioid utilization - in patients with VCF. Trends in opioid prescription fills were evaluated in the 7 months after intervention, less a 1-month, postprocedure washout period, relative to use in the 6 months prior to surgical intervention. Overall, $57.1 \%$ of patients 
Fig. 2 Opioid prescription days (A) and average daily dose, in MME (B) before and after vertebral augmentation, by opioid prescription trend.**Vertical dashed line: index procedure date. Opioid prescription fills during the washout period were excluded from analysis. Patients with no evidence of opioid prescription fills during study period were also excluded
A Opioid prescription days, balloon kyphoplasty or vertebroplasty

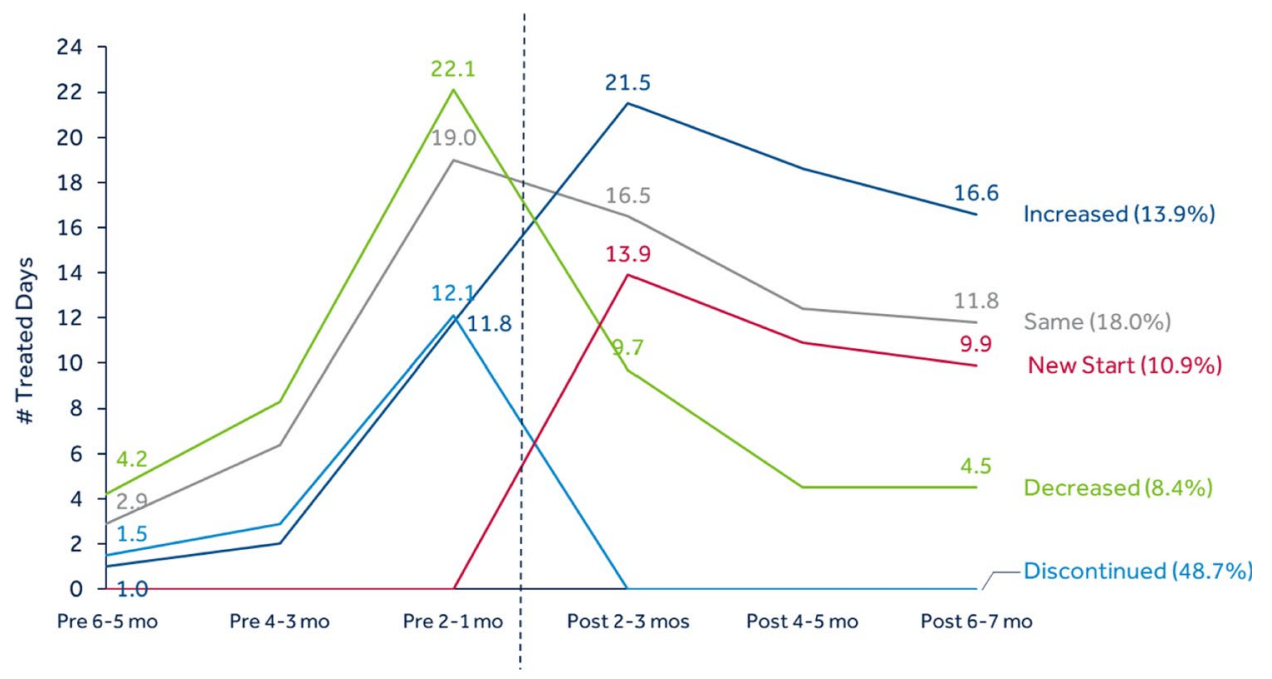

B Average daily dose (MME), balloon kyphoplasty or vertebroplasty

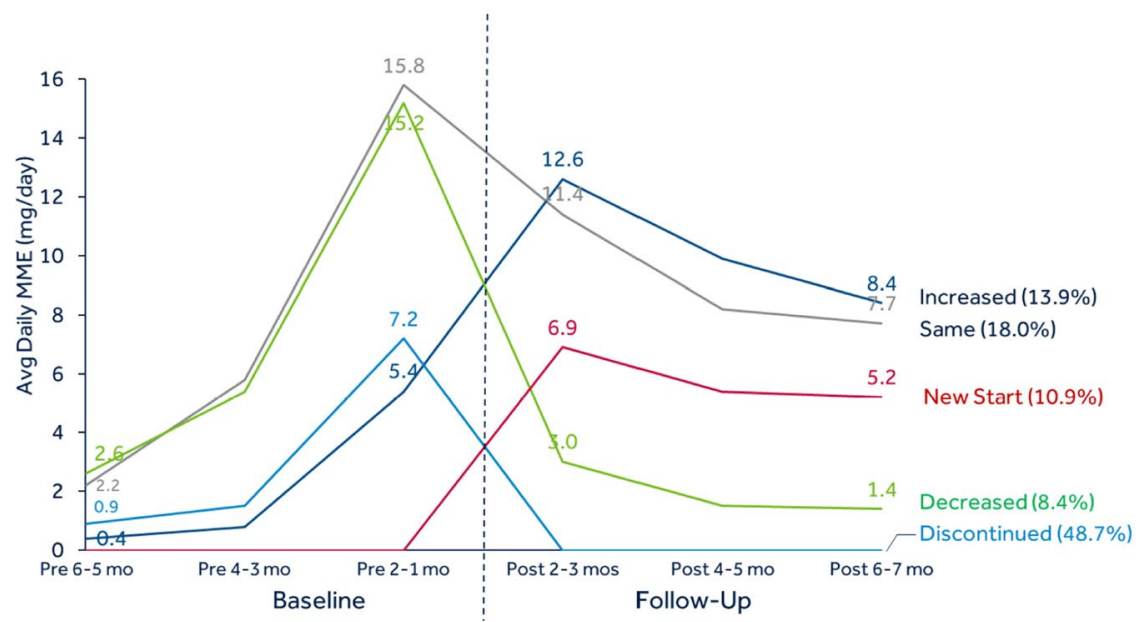

discontinued or reduced prescription fills within 7 months after vertebral augmentation versus preoperative baseline levels.

Our observations are consistent with prior evidence that opioid use decreases after either a BKP or VP procedure. Two previous clinical trials comparing VP to CMM found that fewer patients treated with VP were using opioid medications at up to 12-month follow-up compared to patients treated with CMM [33, 34]. A randomized controlled trial comparing BKP to CMM found a statistically significant reduction in opioid use in BKP patients after 6 months, although this difference was no longer observed at 12 or 24 months [35]. Additionally, a multi-center trial comparing BKP to VP showed that the percentage of patients treated with opioids was significantly reduced at the 6-month follow-up relative to baseline in both cohorts, although the difference between patients in the two treatment cohorts was not significant [36].
These studies drew their conclusions from small study populations - usually less than 200 patients - and clinical trials that were not necessarily designed or powered with changes in opioid use as a primary outcome. Therefore, the present study is unique in that it evaluates the impact of these procedures on opioid prescription fills as a primary outcome, using a larger, real-world study population.

The average baseline daily MME was approximately 5 $\mathrm{mg} /$ day, with an average of 22 treated days. This represents a relatively low-dose opioid regimen compared to patients being treated for chronic back pain and is not a level most commonly associated with the current epidemic of persistent opioid use and opioid-use disorders [37]. However, it is notable that patients in this analysis were elderly, with an average age of 77 years.

Opioids are one of the most effective ways to manage short-term pain, but in the elderly they are associated with enhanced risk of adverse events due to changes in 
Table 3 Logistic regression: factors associated with avg daily MME dose reduction to a lower dose category or opioid discontinuation (conditional upon any opioid prescription fill in baseline or follow-up)

\begin{tabular}{lllll}
\hline Variable & Odds ratio & Lower CI & Upper CI & $\operatorname{Pr}(>\mid \mathrm{zl})$ \\
\hline (Intercept) & & & & 0.0615 \\
Age group: 65 and up & 1.15 & 1.01 & 1.31 & 0.0364 \\
Gender: Male & 1.09 & 0.97 & 1.22 & 0.1391 \\
Charlson Score Group: 1 & 0.8 & 0.71 & 0.91 & 0.0005 \\
Charlson Score Group: 2+ & 0.82 & 0.73 & 0.93 & 0.0025 \\
Region: South & 0.98 & 0.83 & 1.15 & 0.7892 \\
Region: West & 1.07 & 0.87 & 1.31 & 0.5314 \\
Region: Midwest & 1.02 & 0.86 & 1.2 & 0.8305 \\
Region: Missing & 1.37 & 0.83 & 2.27 & 0.2232 \\
Baseline Diagnosis Osteopenia & 1.11 & 0.95 & 1.29 & 0.1806 \\
Baseline Diagnosis Osteoporosis & 1.37 & 1.23 & 1.53 & $<0.0001$ \\
Days from VCF to Surgery Group: 8-14 & 1.62 & 1.4 & 1.88 & $<0.0001$ \\
Days from VCF to Surgery Group: 15-21 & 1.86 & 1.56 & 2.23 & $<0.0001$ \\
Days from VCF to Surgery Group: 22-27 & 1.62 & 1.28 & 2.04 & $<0.0001$ \\
Days from VCF to Surgery Group: 28+ & 1.59 & 1.4 & 1.81 & $<0.0001$ \\
Baseline Anticonvulsants Prescription & 0.92 & 0.82 & 1.03 & 0.1302 \\
Baseline Muscle Relaxant Prescription & 1.26 & 1.13 & 1.41 & $<0.0001$ \\
\hline
\end{tabular}

Source: MDT Truven CCAE/MDCR 2008-2018

Logistic regression was performed to identify risk factors

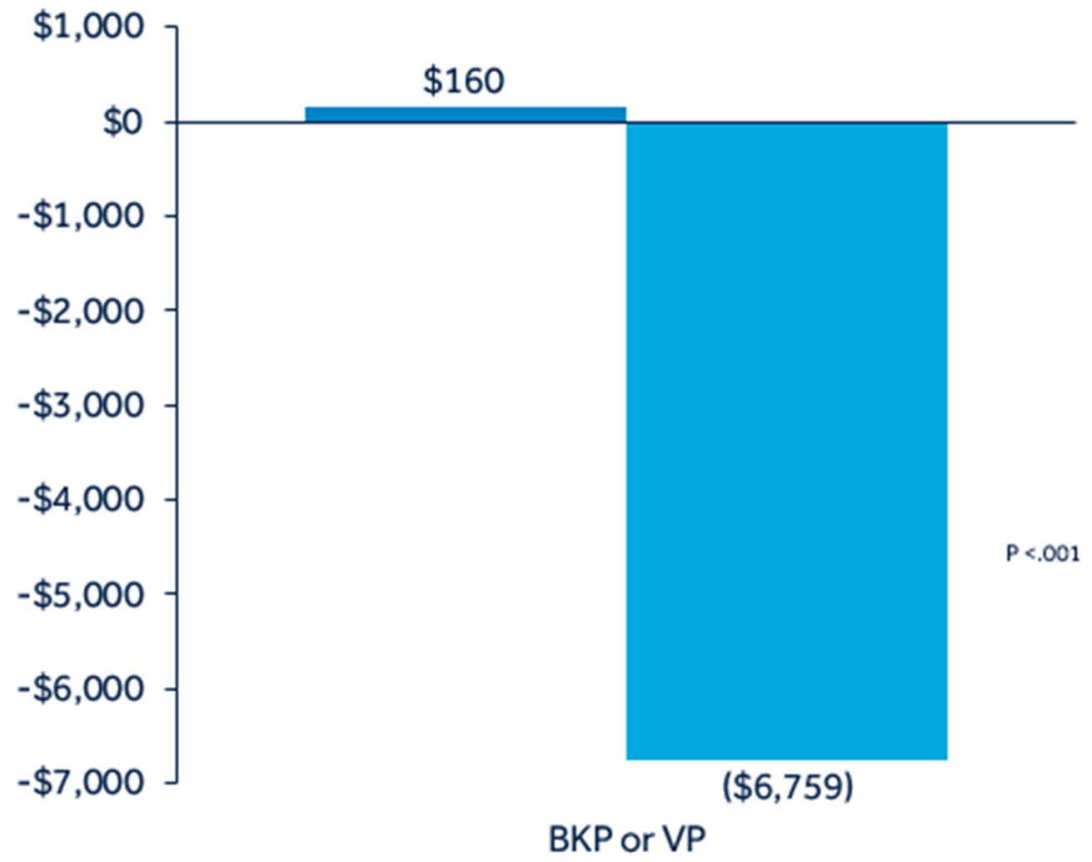

Same, Increased, or New Start Decreased or Discontinued
Fig. 3 Difference in adjusted all-cause payer costs in follow-up versus baseline, stratified by opioid prescription trend after a vertebral augmentation procedure. Opioid prescription fills during the washout

physiology, drug metabolism, and elimination associated with aging, even at low doses [25]. The side effects include constipation, nausea, urinary retention, respiratory depression, balance dysregulation, elevated fall risk, and changes period was excluded from analysis. Subjects with no evidence of opioid prescription fills during study period were also excluded

in mental status [25, 27, 28]. Notably, opioid use longer than 12 weeks in geriatric patients is associated with an $80 \%$ increase in opioid-associated adverse reactions compared to shorter duration of use [26]. For these reasons, the American 
Geriatric Society 2009 guidelines for management of persistent pain in older adults recommend initiating opiates at the lowest dose possible, approximately $25-50 \%$ of the adult recommended dose [24, 25, 38].

Even when doses are low, reducing, tapering, and discontinuing opioid regimens as much as possible helps to minimize adverse events and has a positive impact on the overall mental and physical well-being of elderly patients [27, 39]. This phenomenon may happen naturally; it has been shown previously that rates of opioid discontinuation among the elderly are as high as $25 \%$ due to poorly tolerated side effects [40]. This rate is consistent with our finding that age greater than 65 years was associated with opioid decrease or discontinuation after a vertebral augmentation procedure. Taking all of these considerations together, we believe it was clinically meaningful to track changes in prescription fills after vertebral augmentation procedures even if the magnitude of the dosage changes were minor.

Given the adverse effects of opioid use among an elderly, medically fragile population such as patients with VCF, the economic impact is likely to be multi-fold. We examined the effect of changes in opioid prescription fills after vertebral augmentation on total healthcare costs from the payer perspective, adjusted for potentially confounding factors such as age, gender, comorbidity status, and presence of historic non-opioid medication use. Our results suggest that decreased or discontinued fills of opioid prescriptions after vertebral augmentation procedures were associated with greater reduction in all-cause healthcare costs (vs pre-surgical costs) relative to patients who did not change, increased, or newly started opioids after surgery. Given the retrospective nature of our analysis, this result only implies correlation, with many unobservable factors in retrospective claims impacting all-cause payer costs beyond opioid prescription patterns.

Finally, an important observation of this study is that the trends in opioid prescription fills were similar in both the $\mathrm{BKP}$ and VP cohorts. This finding is not surprising given the difference in radiographic outcomes by approach may not be enough to vary pain outcomes - and therefore the need for opioid analgesics-across the two surgical approaches.

\section{Study limitations}

This study has a number of limitations due to its nature as a retrospective analysis from a predefined database of medical claims. Foremost, it was not possible to evaluate patient consumption of opioids directly, and instead we had to use prescription fills as a surrogate measure for opioid consumption. Patients who fill an opioid prescription may or may not consume all medication for a variety of reasons, and it was not possible to account for actual usage. Patient-reported pain scores and functional status were not available, precluding a direct analysis of the effects of BKP or VP procedures on pain relief. The study was also not able to control for how other chronic, non-VCF conditions influenced patients' choice to fill opioid prescriptions.

Additionally, available data were limited to prescription medications filled and paid for by the patient's insurance plan. Cash or self-pay options for prescription medications were not collected in this dataset. Therefore, our estimates of opioid prescription fills may have been affected if patients with insurance chose to pay out of pocket for their prescriptions. Our estimates were also sensitive to miscoding of pharmacy claims data for days' supply, quantity, strength, and number of units.

It is possible that some of the prescription behavior observed in this analysis is that of the physicians and not necessarily the patients. Often prescriptions are written by the physician to have pro re nata, which may affect our conclusions if the patients did not actually consume them. Future research would be needed to understand prescribing behavior.

Finally, we were unable to include a control cohort of patients treated with CMM. Despite multiple attempts to apply propensity-score matching models, baseline opioid prescription fills remained higher in the intervention cohorts relative to CMM. We assumed that the most important confounding patient characteristic of pain intensity, which is not available in administrative claims, was driving these results and therefore the inability to select an appropriately match CMM comparator. In any case, the 6-month baseline, with data collected prior to surgical intervention, was designed to mitigate this limitation by providing a within-patient comparison as opposed to comparison to a CMM group.

\section{Conclusions}

This study showed that VCF patients who underwent vertebral augmentation, including balloon kyphoplasty or vertebroplasty procedures, significantly changed their patterns of opioid prescription fills following surgical intervention with corresponding decreases in all-cause post-surgical payer costs compared to baseline costs. Considering the known clinical risks of unaddressed VCF, the benefits of minimizing opioid use in the elderly, and the economic benefit of reducing all-cause payer costs, our findings add to the argument favoring vertebral augmentation-whether BKP or VP-over CMM as a treatment strategy to address VCF. 


\section{Appendix 1}

Table 4 Codes list for patient selection

\begin{tabular}{|c|c|c|}
\hline $\begin{array}{l}\text { Inclusion/exclu- } \\
\text { sion }\end{array}$ & Code & Description \\
\hline \multirow[t]{13}{*}{ BKP } & OPS43ZZ & $\begin{array}{l}\text { Reposition Thoracic Vertebra, Percutaneous Approach (requires reposition AND supplement } \\
\text { ICD10s to be BKP) }\end{array}$ \\
\hline & 0QS03ZZ & $\begin{array}{l}\text { Reposition Lumbar Vertebra, Percutaneous Approach (requires reposition AND supplement } \\
\text { ICD10s to be BKP) }\end{array}$ \\
\hline & 0QS13ZZ & $\begin{array}{l}\text { Reposition Sacrum, Percutaneous Approach (requires reposition AND supplement ICD10s to be } \\
\text { BKP) }\end{array}$ \\
\hline & 0PU43JZ & $\begin{array}{l}\text { Supplement Thoracic Vertebra with Synthetic Substitute, Percutaneous Approach (requires repo- } \\
\text { sition AND supplement ICD10s to be BKP) }\end{array}$ \\
\hline & 0QU03JZ & $\begin{array}{l}\text { Supplement Lumbar Vertebra with Synthetic Substitute, Percutaneous Approach (requires reposi- } \\
\text { tion AND supplement ICD10s to be BKP) }\end{array}$ \\
\hline & 0QU13JZ & $\begin{array}{l}\text { Supplement Sacrum with Synthetic Substitute, Percutaneous Approach (requires reposition AND } \\
\text { supplement ICD10s to be BKP) }\end{array}$ \\
\hline & 22513 & $\begin{array}{l}\text { Percutaneous vertebral augmentation, including cavity creation (fracture reduction and bone } \\
\text { biopsy included when performed) using mechanical device (e.g., kyphoplasty), } 1 \text { vertebral } \\
\text { body, unilateral or bilateral cannulation, inclusive of all imaging guidance; thoracic }\end{array}$ \\
\hline & 22514 & $\begin{array}{l}\text { Percutaneous vertebral augmentation, including cavity creation (fracture reduction and bone } \\
\text { biopsy included when performed) using mechanical device (e.g., kyphoplasty), } 1 \text { vertebral } \\
\text { body, unilateral or bilateral cannulation, inclusive of all imaging guidance; lumbar }\end{array}$ \\
\hline & 22515 & $\begin{array}{l}\text { Percutaneous vertebral augmentation, including cavity creation (fracture reduction and bone } \\
\text { biopsy included when performed) using mechanical device (e.g., kyphoplasty), } 1 \text { vertebral } \\
\text { body, unilateral or bilateral cannulation, inclusive of all imaging guidance; each additional } \\
\text { thoracic or lumbar vertebral body (List separately in addition to code for primary procedure) }\end{array}$ \\
\hline & 22523 & $\begin{array}{l}\text { Percutaneous vertebral augmentation, including cavity creation (fracture reduction and bone } \\
\text { biopsy included when performed) using mechanical device, } 1 \text { vertebral body, unilateral or bilat- } \\
\text { eral cannulation (e.g., kyphoplasty); thoracic }\end{array}$ \\
\hline & 22524 & $\begin{array}{l}\text { Percutaneous vertebral augmentation, including cavity creation (fracture reduction and bone } \\
\text { biopsy included when performed) using mechanical device, } 1 \text { vertebral body, unilateral or bilat- } \\
\text { eral cannulation (e.g., kyphoplasty); lumbar }\end{array}$ \\
\hline & 22525 & $\begin{array}{l}\text { Percutaneous vertebral augmentation, including cavity creation (fracture reduction and bone } \\
\text { biopsy included when performed) using mechanical device, } 1 \text { vertebral body, unilateral or } \\
\text { bilateral cannulation (e.g., kyphoplasty); each additional thoracic or lumbar vertebral body (List } \\
\text { separately in addition to code for primary procedure) }\end{array}$ \\
\hline & 81.66 & Percutaneous vertebral augmentation \\
\hline \multirow[t]{8}{*}{ VP } & OPU43JZ & $\begin{array}{l}\text { Supplement Thoracic Vertebra with Synthetic Substitute, Percutaneous Approach (requires NO } \\
\text { reposition ICD10 be VP) }\end{array}$ \\
\hline & 0QU03JZ & $\begin{array}{l}\text { Supplement Thoracic Vertebra with Synthetic Substitute, Percutaneous Approach (requires NO } \\
\text { reposition ICD10 be VP) }\end{array}$ \\
\hline & 0QU13JZ & $\begin{array}{l}\text { Supplement Thoracic Vertebra with Synthetic Substitute, Percutaneous Approach (requires NO } \\
\text { reposition ICD10 be VP) }\end{array}$ \\
\hline & 22510 & $\begin{array}{l}\text { Percutaneous vertebroplasty (bone biopsy included when performed), } 1 \text { vertebral body, unilateral } \\
\text { or bilateral injection, inclusive of all imaging guidance; cervicothoracic }\end{array}$ \\
\hline & 22511 & $\begin{array}{l}\text { Percutaneous vertebroplasty (bone biopsy included when performed), } 1 \text { vertebral body, unilateral } \\
\text { or bilateral injection, inclusive of all imaging guidance; lumbosacral }\end{array}$ \\
\hline & 22512 & $\begin{array}{l}\text { Percutaneous vertebroplasty (bone biopsy included when performed), } 1 \text { vertebral body, unilateral } \\
\text { or bilateral injection, inclusive of all imaging guidance; each additional cervicothoracic or lum- } \\
\text { bosacral vertebral body (List separately in addition to code for primary procedure) }\end{array}$ \\
\hline & 22520 & $\begin{array}{l}\text { Percutaneous vertebroplasty (bone biopsy included when performed), } 1 \text { vertebral body, unilateral } \\
\text { or bilateral injection; thoracic }\end{array}$ \\
\hline & 22521 & $\begin{array}{l}\text { Percutaneous vertebroplasty (bone biopsy included when performed), } 1 \text { vertebral body, unilateral } \\
\text { or bilateral injection; lumbar }\end{array}$ \\
\hline
\end{tabular}


Table 4 (continued)

\begin{tabular}{|c|c|c|}
\hline $\begin{array}{l}\text { Inclusion/exclu- } \\
\text { sion }\end{array}$ & Code & Description \\
\hline & 22522 & $\begin{array}{l}\text { Percutaneous vertebroplasty (bone biopsy included when performed), } 1 \text { vertebral body, unilateral } \\
\text { or bilateral injection; each additional thoracic or lumbar vertebral body (List separately in addi- } \\
\text { tion to code for primary procedure) }\end{array}$ \\
\hline & 81.65 & Percutaneous vertebroplasty \\
\hline \multirow[t]{3}{*}{ Pathologic VCF } & M80.08XA & $\begin{array}{l}\text { Age-related osteoporosis with current pathological fracture, vertebra(e), initial encounter for } \\
\text { fracture }\end{array}$ \\
\hline & M80.88XA & Other osteoporosis with current pathological fracture, vertebra(e), initial encounter for fracture \\
\hline & 733.13 & Pathologic fracture of vertebrae \\
\hline Neoplasm fracture & M84.50XA-M84.58XS & Pathological fracture in neoplastic disease \\
\hline \multirow{38}{*}{$\begin{array}{l}\text { History opioid } \\
\text { abuse/depend- } \\
\text { ence }\end{array}$} & 965.00 & Poisoning by opium (alkaloids), unspecified \\
\hline & 965.01 & Poisoning by heroin \\
\hline & 965.02 & Poisoning by methadone \\
\hline & 965.09 & Poisoning by other opiates and related narcotics \\
\hline & 970.1 & Poisoning by opiate antagonists \\
\hline & E850.0 & Accidental poisoning by heroin \\
\hline & E850.1 & Accidental poisoning by methadone \\
\hline & E850.2 & Accidental poisoning by other opiates and related narcotics \\
\hline & E935.0 & Heroin causing adverse effects in therapeutic use \\
\hline & E935.1 & Methadone causing averse effects in therapeutic use \\
\hline & E935.2 & Other opiates and related narcotics causing adverse effects in therapeutic use \\
\hline & E940.1 & Opiate antagonists causing adverse effects in therapeutic use \\
\hline & $\mathrm{T} 40.0 \mathrm{X} 1 \mathrm{~A}$ & Poisoning by opium, accidental (unintentional), initial encounter \\
\hline & $\mathrm{T} 40.0 \mathrm{X} 2 \mathrm{~A}$ & Poisoning by opium, intentional self-harm, initial encounter \\
\hline & $\mathrm{T} 40.0 \mathrm{X} 4 \mathrm{~A}$ & Poisoning by opium, undetermined, initial encounter \\
\hline & $\mathrm{T} 40.1 \mathrm{X} 1 \mathrm{~A}$ & Poisoning by heroin, accidental (unintentional), initial encounter \\
\hline & $\mathrm{T} 40.1 \mathrm{X} 2 \mathrm{~A}$ & Poisoning by heroin, intentional self-harm, initial encounter \\
\hline & T40.1X4A & Poisoning by heroin, undetermined, initial encounter \\
\hline & $\mathrm{T} 40.2 \mathrm{X} 1 \mathrm{~A}$ & Poisoning by other opioids, accidental (unintentional), initial encounter \\
\hline & $\mathrm{T} 40.2 \mathrm{X} 2 \mathrm{~A}$ & Poisoning by other opioids, intentional self-harm, initial encounter \\
\hline & $\mathrm{T} 40.2 \mathrm{X} 4 \mathrm{~A}$ & Poisoning by other opioids, undetermined, initial encounter \\
\hline & $\mathrm{T} 40.3 \mathrm{X} 1 \mathrm{~A}$ & Poisoning by methadone, accidental (unintentional), initial encounter \\
\hline & $\mathrm{T} 40.3 \mathrm{X} 2 \mathrm{~A}$ & Poisoning by methadone, intentional self-harm, initial encounter \\
\hline & $\mathrm{T} 40.3 \mathrm{X} 4 \mathrm{~A}$ & Poisoning by methadone, undetermined, initial encounter \\
\hline & $\mathrm{T} 40.4 \mathrm{X} 1 \mathrm{~A}$ & Poisoning by other synthetic narcotics, accidental (unintentional), initial encounter \\
\hline & $\mathrm{T} 40.4 \mathrm{X} 2 \mathrm{~A}$ & Poisoning by other synthetic narcotics, intentional self-harm, initial encounter \\
\hline & $\mathrm{T} 40.4 \mathrm{X} 4 \mathrm{~A}$ & Poisoning by other synthetic narcotics, undetermined, initial encounter \\
\hline & $\mathrm{T} 40.601 \mathrm{~A}$ & Poisoning by unspecified narcotics, accidental (unintentional), initial encounter \\
\hline & $\mathrm{T} 40.602 \mathrm{~A}$ & Poisoning by unspecified narcotics, intentional self-harm, initial encounter \\
\hline & $\mathrm{T} 40.604 \mathrm{~A}$ & Poisoning by unspecified narcotics, undetermined, initial encounter \\
\hline & $\mathrm{T} 40.691 \mathrm{~A}$ & Poisoning by other narcotics, accidental (unintentional), initial encounter \\
\hline & $\mathrm{T} 40.692 \mathrm{~A}$ & Poisoning by other narcotics, intentional self-harm, initial encounter \\
\hline & T40.694A & Poisoning by other narcotics, undetermined, initial encounter \\
\hline & T50.7X1A & $\begin{array}{l}\text { Poisoning by analeptics and opioid receptor antagonists, accidental (unintentional), initial } \\
\text { encounter }\end{array}$ \\
\hline & T50.7X2A & Poisoning by analeptics and opioid receptor antagonists, intentional self-harm, initial encounter \\
\hline & T50.7X4A & Poisoning by analeptics and opioid receptor antagonists, undetermined, initial encounter \\
\hline & 305.50 & Opioid abuse, unspecified \\
\hline & 305.51 & Opioid abuse, continuous \\
\hline
\end{tabular}


Table 4 (continued)

\begin{tabular}{|c|c|c|}
\hline $\begin{array}{l}\text { Inclusion/exclu- } \\
\text { sion }\end{array}$ & Code & Description \\
\hline & 305.52 & Opioid abuse, episodic \\
\hline & 305.53 & Opioid abuse, in remission \\
\hline & F11.10 & Opioid abuse, uncomplicated \\
\hline & F11.11 & Opioid abuse, in remission \\
\hline & F11.120 & Opioid abuse with intoxication, uncomplicated \\
\hline & F11.121 & Opioid abuse with intoxication delirium \\
\hline & F11.122 & Opioid abuse with intoxication with perceptual disturbance \\
\hline & F11.129 & Opioid abuse with intoxication, unspecified \\
\hline & F11.14 & Opioid abuse with opioid-induced mood disorder \\
\hline & F11.150 & Opioid abuse with opioid-induced psychotic disorder with delusions \\
\hline & F11.151 & Opioid abuse with opioid-induced psychotic disorder with hallucinations \\
\hline & F11.159 & Opioid abuse with opioid-induced psychotic disorder, unspecified \\
\hline & F11.181 & Opioid abuse with opioid-induced sexual dysfunction \\
\hline & F11.182 & Opioid abuse with opioid-induced sleep disorder \\
\hline & F11.188 & Opioid abuse with other opioid-induced disorder \\
\hline & F11.19 & Opioid abuse with unspecified opioid-induced disorder \\
\hline & 304.00 & Opioid type dependence, unspecified \\
\hline & 304.01 & Opioid type dependence, continuous \\
\hline & 304.02 & Opioid type dependence, episodic \\
\hline & 304.70 & Combinations of opioid type drug with any other drug dependence, unspecified \\
\hline & 304.71 & Combinations of opioid type drug with any other drug dependence, continuous \\
\hline & 304.72 & Combinations of opioid type drug with any other drug dependence, episodic \\
\hline & F11.20 & Opioid dependence, uncomplicated \\
\hline & F11.21 & Opioid dependence, in remission \\
\hline & F11.220 & Opioid dependence with intoxication, uncomplicated \\
\hline & F11.221 & Opioid dependence with intoxication delirium \\
\hline & F11.222 & Opioid dependence with intoxication with perceptual disturbance \\
\hline & F11.229 & Opioid dependence with intoxication, unspecified \\
\hline & F11.23 & Opioid dependence with withdrawal \\
\hline & F11.24 & Opioid dependence with opioid-induced mood disorder \\
\hline & F11.250 & Opioid dependence with opioid-induced psychotic disorder with delusions \\
\hline & F11.251 & Opioid dependence with opioid-induced psychotic disorder with hallucinations \\
\hline & F11.259 & Opioid dependence with opioid-induced psychotic disorder, unspecified \\
\hline & F11.281 & Opioid dependence with opioid-induced sexual dysfunction \\
\hline & F11.282 & Opioid dependence with opioid-induced sleep disorder \\
\hline & F11.288 & Opioid dependence with other opioid-induced disorder \\
\hline & F11.29 & Opioid dependence with unspecified opioid-induced disorder \\
\hline & F19.20 & Other psychoactive substance dependence, uncomplicated \\
\hline
\end{tabular}




\section{Appendix 2}

Table 5 Opioid conversion factors to MME

\begin{tabular}{|c|c|c|c|}
\hline Name & Strength & $\begin{array}{l}\text { Conver- } \\
\text { sion } \\
\text { factor }\end{array}$ & Source \\
\hline Alfentanil sc & $\operatorname{mcg}$ & 30 & Palliative Care guidelines 2016 \\
\hline Buprenorphine film & $\mathrm{mcg} / \mathrm{hr}$ & 12.6 & CDC 2018 and CMS 2017 (footnote 4) \\
\hline Buprenorphine film, extended release & $\mathrm{mcg} / \mathrm{hr}$ & 12.6 & CDC 2018 and CMS 2017 (footnote 4) \\
\hline Buprenorphine tablet & $\mathrm{mg}$ & 30 & CMS 2017 \\
\hline Buprenorphine iv/sc & $\mathrm{mg} / \mathrm{mL}$ & 33 & Buprenorphine label \\
\hline Buprenorphine solution & $\mathrm{mg} / \mathrm{mL}$ & 33 & Buprenorphine label \\
\hline Buprenorphine powder & & & N/A cannot assign conversion for powers (compounding) \\
\hline Butorphanol iv/sc & $\mathrm{mg}$ & 7 & CDC 2018 \\
\hline Butorphanol solution & $\mathrm{mg}$ & 7 & CDC 2018 \\
\hline Butorphanol spray & $\mathrm{mg}$ & 7 & CDC 2018 \\
\hline Codeine tablet & $\mathrm{mg}$ & 0.15 & CDC 2018 \\
\hline Codeine capsule & $\mathrm{mg}$ & 0.15 & CDC 2018 \\
\hline Codeine iv/sc & $\mathrm{mg}$ & 0.15 & CDC 2018 \\
\hline Codeine solution & $\mathrm{mg} /$ day & 0.15 & CDC 2018 \\
\hline Codeine liquid & $\mathrm{mg} /$ day & 0.15 & CDC 2018 \\
\hline Codeine suspension & $\mathrm{mg} /$ day & 0.15 & CDC 2018 \\
\hline Codeine powder & & & N/A cannot assign conversion for powers (compounding) \\
\hline Dezocine & & & No longer commercially available (2011) \\
\hline Fentanyl film or oral spray & $\operatorname{mcg}$ & 0.18 & CDC 2018 \\
\hline Fentanyl film, extended release & $\mathrm{mcg}$ & 0.18 & CDC 2018 \\
\hline Fentanyl film & $\mathrm{mcg}$ & 0.18 & CDC 2018 \\
\hline Fentanyl nasal spray & $\mathrm{mcg}$ & 0.16 & CDC 2018 \\
\hline Fentanyl spray & $\operatorname{mcg}$ & 0.16 & CDC 2018 \\
\hline Fentanyl patch & $\mathrm{mcg} / \mathrm{hr}$ & 7.2 & CDC 2018 and CMS 2017 (footnote 8) \\
\hline Fentanyl tablet & $\mathrm{mcg}$ & 0.13 & CDC 2018 \\
\hline Fentanyl lozenge & $\mathrm{mcg}$ & 0.13 & CDC 2018 \\
\hline Fentanyl iv/sc & $\operatorname{mcg}$ & 0.13 & Assumption - consistent with other routes of administration in CDC 2018 for opioid class \\
\hline Fentanyl solution & $\operatorname{mcg}$ & 0.13 & Assumption - consistent with other routes of administration in CDC 2018 for opioid class \\
\hline Fentanyl solution, extended release & $\operatorname{mcg}$ & 0.13 & Assumption - consistent with other routes of administration in CDC 2018 for opioid class \\
\hline Fentanyl powder & & & N/A cannot assign conversion for powers (compounding) \\
\hline Hydrocodone & $\mathrm{mg}$ & 1 & CDC 2018 \\
\hline Hydrocodone powder & $\mathrm{mg}$ & & N/A cannot assign conversion for powers (compounding) \\
\hline Hydrocodone capsule, extended release & $\mathrm{mg}$ & 1 & CDC 2018 \\
\hline Hydrocodone tablet, extended release & $\mathrm{mg}$ & 1 & CDC 2018 \\
\hline Hydrocodone tablet & $\mathrm{mg}$ & 1 & CDC 2018 \\
\hline Hydrocodone capsule & $\mathrm{mg}$ & 1 & CDC 2018 \\
\hline Hydrocodone elixir & $\mathrm{mg}$ & 1 & CDC 2018 \\
\hline Hydrocodone liquid & $\mathrm{mg}$ & 1 & CDC 2018 \\
\hline Hydrocodone solution & $\mathrm{mg}$ & 1 & CDC 2018 \\
\hline Hydromorphone oral & $\mathrm{mg}$ & 4 & CDC 2018 \\
\hline Hydromorphone capsule, extended release & $\mathrm{mg}$ & 4 & CDC 2018 \\
\hline Hydromorphone tablet & $\mathrm{mg}$ & 4 & CDC 2018 \\
\hline Hydromorphone tablet, extended release & $\mathrm{mg}$ & 4 & CDC 2018 \\
\hline Hydromorphone iv/sc & $\mathrm{mg}$ & 4 & Assumption - consistent with other routes of administration in CDC 2018 for opioid class \\
\hline Hydromorphone solution & $\mathrm{mg}$ & 4 & Assumption - consistent with other routes of administration in CDC 2018 for opioid class \\
\hline Hydromorphone liquid & $\mathrm{mg}$ & 4 & Assumption - consistent with other routes of administration in CDC 2018 for opioid class \\
\hline Hydromorphone suppository & & & N/A cannot assign conversion for powers (compounding) \\
\hline Hydromorphone powder & & & N/A cannot assign conversion for powers (compounding) \\
\hline
\end{tabular}


Table 5 (continued)

\begin{tabular}{|c|c|c|c|}
\hline Name & Strength & $\begin{array}{l}\text { Conver- } \\
\text { sion } \\
\text { factor }\end{array}$ & Source \\
\hline Hydromorphone powder, extended release & & & N/A cannot assign conversion for powers (compounding) \\
\hline Levomethadyl acetate oral & $\mathrm{mg}$ & 8 & CDC 2018 \\
\hline Levomethadyl acetate iv/sc & $\mathrm{mg}$ & 8 & CDC 2018 \\
\hline Levorphanol oral & $\mathrm{mg}$ & 11 & CDC 2018 \\
\hline Levorphanol tablet & $\mathrm{mg}$ & 11 & CDC 2018 \\
\hline Levorphanol iv/sc & $\mathrm{mg}$ & 11 & Assumption - consistent with other routes of administration in CDC 2018 for opioid class \\
\hline Levorphanol solution & $\mathrm{mg}$ & 11 & Assumption - consistent with other routes of administration in CDC 2018 for opioid class \\
\hline Levorphanol powder & & & N/A cannot assign conversion for powers (compounding) \\
\hline Meperidine oral & $\mathrm{mg}$ & 0.1 & CDC 2018 \\
\hline Meperidine tablet & $\mathrm{mg}$ & 0.1 & CDC 2018 \\
\hline Meperidine capsule & $\mathrm{mg}$ & 0.1 & Assumption - consistent with other routes of administration in CDC 2018 for opioid class \\
\hline Meperidine syrup & $\mathrm{mg}$ & 0.1 & CDC 2018 \\
\hline Meperidine iv/sc & $\mathrm{mg}$ & 0.1 & Assumption - consistent with other routes of administration in CDC 2018 for opioid class \\
\hline Meperidine solution & $\mathrm{mg}$ & 0.1 & Assumption - consistent with other routes of administration in CDC 2018 for opioid class \\
\hline Meperidine powder & & & N/A cannot assign conversion for powers (compounding) \\
\hline Methadone tablet & $\mathrm{mg}$ & 3 & CDC 2018 \\
\hline Methadone tablet, dispersible & $\mathrm{mg}$ & 3 & CDC 2018 \\
\hline Methadone concentrate & $\mathrm{mg}$ & 3 & Assumption - consistent with other routes of administration in CDC 2018 for opioid class \\
\hline Methadone solution & $\mathrm{mg}$ & 3 & CDC 2018 \\
\hline Methadone powder & & 3 & Assumption - consistent with other routes of administration in CDC 2018 for opioid class \\
\hline Methadone injectable solution & $\mathrm{mg} / \mathrm{mL}$ & 3 & Assumption - consistent with other routes of administration in CDC 2018 for opioid class \\
\hline Morphine oral & $\mathrm{mg}$ & 1 & CDC 2018 \\
\hline Morphine capsule, extended release & $\mathrm{mg}$ & 1 & CDC 2018 \\
\hline Morphine tablet & $\mathrm{mg}$ & 1 & CDC 2018 \\
\hline Morphine tablet, extended release & $\mathrm{mg}$ & 1 & CDC 2018 \\
\hline Morphine tablet, soluble & $\mathrm{mg}$ & 1 & CDC 2018 \\
\hline Morphine rectal & $\mathrm{mg}$ & 1 & CDC 2018 \\
\hline Morphine suppository & $\mathrm{mg}$ & 1 & CDC 2018 \\
\hline Morphine iv/sc & $\mathrm{mg} / \mathrm{mL}$ & 1 & Assumption - consistent with other routes of administration in CDC 2018 for opioid class \\
\hline Morphine solution & $\mathrm{mg} / \mathrm{mL}$ & 1 & Assumption - consistent with other routes of administration in CDC 2018 for opioid class \\
\hline Morphine Sulfate Immediate Release & $\mathrm{mg}$ & 1 & \\
\hline Morphine Sulfate Immediate Release & $\mathrm{mg} / \mathrm{mL}$ & 1 & \\
\hline Morphine capsule & $\mathrm{mg}$ & 1 & \\
\hline Morphine liquid & $\mathrm{mg} / \mathrm{mL}$ & 1 & Assumption - consistent with other routes of administration in CDC 2018 for opioid class \\
\hline Morphine concentrate & $\mathrm{mg} / \mathrm{mL}$ & 1 & Assumption - consistent with other routes of administration in CDC 2018 for opioid class \\
\hline Morphine powder & & & N/A cannot assign conversion for powers (compounding) \\
\hline Morphine tincture & & & N/A cannot assign conversion for powers (compounding) \\
\hline Morphine suppository & $\mathrm{mg}$ & 1 & \\
\hline Morphine suspension, extended release & $\mathrm{mg} / \mathrm{mL}$ & 1 & \\
\hline MS/S & $\mathrm{mg}$ & 1 & \\
\hline MSIR & $\mathrm{mg}$ & 1 & \\
\hline Nalbuphine & $\mathrm{mg} /$ day & 3 & Nielsen 2015 \\
\hline Nalbuphine solution & $\mathrm{mg} /$ day & 3 & Nielsen 2015 \\
\hline Nalbuphine powder & & & N/A cannot assign conversion for powers (compounding) \\
\hline Opium & $\mathrm{mg}$ & 1 & CDC 2018 \\
\hline Opium suppository & $\mathrm{mg}$ & 1 & Assumption - consistent with other routes of administration in CDC 2018 for opioid class \\
\hline Oxycodone & $\mathrm{mg}$ & 1.5 & CDC 2018 \\
\hline Oxycodone capsule, extended release & $\mathrm{mg}$ & 1.5 & CDC 2018 \\
\hline Oxycodone capsule & $\mathrm{mg}$ & 1.5 & CDC 2018 \\
\hline Oxycodone tablet & $\mathrm{mg}$ & 1.5 & CDC 2018 \\
\hline Oxycodone tablet, extended release & $\mathrm{mg}$ & 1.5 & CDC 2018 \\
\hline Oxycodone concentrate & $\mathrm{mg} / \mathrm{ml}$ & 1.5 & Assumption - consistent with other routes of administration in CDC 2018 for opioid class \\
\hline Oxycodone powder & & & N/A cannot assign conversion for powers (compounding) \\
\hline
\end{tabular}


Table 5 (continued)

\begin{tabular}{|c|c|c|c|}
\hline Name & Strength & $\begin{array}{l}\text { Conver- } \\
\text { sion } \\
\text { factor }\end{array}$ & Source \\
\hline Oxycodone solution & $\mathrm{mg} / \mathrm{ml}$ & 1.5 & Assumption - consistent with other routes of administration in CDC 2018 for opioid class \\
\hline Oxymorphone & $\mathrm{mg}$ & 3 & CDC 2018 \\
\hline Oxymorphone tablet & $\mathrm{mg}$ & 3 & CDC 2018 \\
\hline Oxymorphone tablet, extended release & mg & 3 & CDC 2018 \\
\hline Oxymorphone injectable solution & & & N/A cannot assign conversion for powers (compounding) \\
\hline Oxymorphone suppository & & 3 & Assumption - consistent with other routes of administration in CDC 2018 for opioid class \\
\hline Pentazocine & $\mathrm{mg}$ & 0.37 & CDC 2018 \\
\hline Pentazocine tablet & $\mathrm{mg}$ & 0.37 & CDC 2018 \\
\hline Pentazocine solution & $\mathrm{mg}$ & 0.37 & CDC 2018 \\
\hline Propoxyphene capsule & $\mathrm{mg}$ & 0.23 & CDC 2018 \\
\hline Propoxyphene tablet & $\mathrm{mg}$ & 0.23 & CDC 2018 \\
\hline \multicolumn{4}{|l|}{ Remifentanil } \\
\hline Sufentanil tablet & $\operatorname{mcg}$ & 2 & \\
\hline Sufentanil solution & mcg/day & 2 & ANZCA Opioid Dose Equivalence \\
\hline Tapentadol tablet & $\mathrm{mg}$ & 0.4 & CDC 2018 \\
\hline Tapentadol tablet, extended release & $\mathrm{mg}$ & 0.4 & CDC 2018 \\
\hline Tramadol capsule, extended release & $\mathrm{mg}$ & 0.1 & CDC 2018 \\
\hline Tramadol tablet & $\mathrm{mg}$ & 0.1 & CDC 2018 \\
\hline Tramadol tablet, disintegrating & $\mathrm{mg}$ & 0.1 & CDC 2018 \\
\hline Tramadol tablet, extended release & $\mathrm{mg}$ & 0.1 & CDC 2018 \\
\hline
\end{tabular}

Conversion factor references:

CDC 2018: National Center for Injury Prevention and Control. CDC compilation of benzodiazepines, muscle relaxants, stimulants, zolpidem, and opioid analgesics with oral morphine milligram equivalent conversion factors, 2018 version. Atlanta

CDC 2018: National Center for Injury Prevention and Control. CDC compilation of benzodiazepines, muscle relaxants, stimulants, zolpidem, and opioid analgesics with oral morphine milligram equivalent conversion factors, 2018 version. Atlanta

Palliative Care Guidelines 2016: http://book.pallcare.info/index.php?tid=125

Buprenorphine label: https://www.naabt.org/documents/buprenex_PI.pdf

Nielsen S, Degenhardt L, Hoban B, Gisev N. A synthesis of oral morphine equivalents (OME) for opioid utilisation studies. Pharmacoepidemiol Drug Saf. 2016 Jun;25(6):733-7. doi: 10.1002/pds.3945.

ANZCA Opioid Dose Equivalence: http://fpm.anzca.edu.au/documents/opioid-dose-equivalence.pdf 
Supplementary Information The online version contains supplementary material available at https://doi.org/10.1007/s00198-021-06163-3.

Acknowledgements The authors thank Jeanne McAdara PhD for professional medical writing assistance with manuscript preparation, which was funded by Medtronic. The authors maintained full freedom of investigation and control over manuscript development.

Conflict of interest WN, CR, MQ, and NG are current or former employees of Medtronic. DJ has nothing to disclose; CJG declares he has served on scientific advisory boards for Eli Lilly, Medtronic, Abbott, Saluda, Spine Biopharma, and Persica and has had research support paid directly to his department from Mainstay Medical and Sollis Therapeutics; JAH declares that he is a consultant for Medtronic, on the DMC of Relievant and a grant recipient from the Neiman Health Policy Institute.

Author contribution WN, CR, MQ, CJG, and JAH designed the study; WN and CR performed the analysis; WN, CR, MQ, NG DJ, CJG, and JAH drafted the manuscript; WN, CR, MQ, NG DJ, CJG, and JAH provided critical review and feedback to the manuscript; all authors approved the final manuscript for submission.

Funding No funding was received related to the research presented in this manuscript. Professional assistance with manuscript preparation was funded by Medtronic Pain Therapies.

Availability of data and materials

Not applicable

Code availability

Not applicable

Declarations

Ethics approval

Not applicable

Consent to participate

Not applicable

Consent for publication

Not applicable

Open Access This article is licensed under a Creative Commons Attribution-NonCommercial 4.0 International License, which permits any non-commercial use, sharing, adaptation, distribution and reproduction in any medium or format, as long as you give appropriate credit to the original author(s) and the source, provide a link to the Creative Commons licence, and indicate if changes were made. The images or other third party material in this article are included in the article's Creative Commons licence, unless indicated otherwise in a credit line to the material. If material is not included in the article's Creative Commons licence and your intended use is not permitted by statutory regulation or exceeds the permitted use, you will need to obtain permission directly from the copyright holder. To view a copy of this licence, visit http://creativecommons.org/licenses/by-nc/4.0/.

\section{References}

1. Baaj AA, Downes K, Vaccaro AR, Uribe JS, Vale FL (2011) Trends in the treatment of lumbar spine fractures in the United States: a socioeconomics perspective: clinical article. J Neurosurg Spine 15:367-370. https://doi.org/10.3171/2011.5.SPINE10934

2. Bliuc D, Nguyen ND, Milch VE, Nguyen TV, Eisman JA, Center JR (2009) Mortality risk associated with low-trauma osteoporotic fracture and subsequent fracture in men and women. JAMA 301:513-521. https://doi.org/10.1001/jama.2009.50
3. Burge R, Dawson-Hughes B, Solomon DH, Wong JB, King A, Tosteson A (2007) Incidence and economic burden of osteoporosis-related fractures in the United States, 2005-2025. J Bone Miner Res 22:465-475. https://doi.org/10.1359/jbmr.061113

4. Johnell O, Kanis JA (2006) An estimate of the worldwide prevalence and disability associated with osteoporotic fractures. Osteoporos Int 17:1726-1733. https://doi.org/10.1007/ s00198-006-0172-4

5. Kendler DL, Bauer DC, Davison KS, Dian L, Hanley DA, Harris ST, McClung MR, Miller PD, Schousboe JT, Yuen CK, Lewiecki EM (2016) Vertebral fractures: clinical importance and management. Am J Med 129:221.e1-221.10. https://doi.org/10.1016/j. amjmed.2015.09.020

6. Musbahi O, Ali AM, Hassany H, Mobasheri R (2018) Vertebral compression fractures. Br J Hosp Med (Lond) 79:36-40. https:// doi.org/10.12968/hmed.2018.79.1.36

7. Hirsch JA, Chandra RV, Carter NS, Beall D, Frohbergh M, Ong K (2020) Number needed to treat with vertebral augmentation to save a life. Am J Neuroradiol 41:178-182. https://doi.org/10.3174/ajnr. A6367

8. Hoyt D, Urits I, Orhurhu V, Orhurhu MS, Callan J, Powell J, Manchikanti L, Kaye AD, Kaye RJ, Viswanath O (2020) Current concepts in the management of vertebral compression fractures. Curr Pain Headache Rep 24:16. https://doi.org/10.1007/ s11916-020-00849-9

9. Hopkins TJ, Eggington S, Quinn M, Nichols-Ricker CI (2020) Cost-effectiveness of balloon kyphoplasty and vertebroplasty versus conservative medical management in the USA. Osteoporos Int 10.1007/s00198-020-05513-x

10. Shonnard NH, Berven S, Anderson PA, Verschuyl E, Norwitz J, Shonnard N, Khor S, Wagoner DD, Yoon ES, Beall DP (2020) Appropriate management of vertebral fragility fractures: development of a pathway based on a vertebral compression fracture registry. Pain Physician 23:E343-E352

11. Chandra RV, Maingard J, Asadi H, Slater LA, Mazwi TL, Marcia S, Barr J, Hirsch JA (2018) Vertebroplasty and kyphoplasty for osteoporotic vertebral fractures: what are the latest data. AJNR Am J Neuroradiol 39:798-806. https://doi.org/10.3174/ajnr.A5458

12. Beall D, Lorio MP, Yun BM, Runa MJ, Ong KL, Warner CB (2018) Review of vertebral augmentation: an updated meta-analysis of the effectiveness. Int J Spine Surg 12:295-321. https://doi. org/10.14444/5036

13. Zuo XH, Zhu XP, Bao HG, Xu CJ, Chen H, Gao XZ, Zhang QX (2018) Network meta-analysis of percutaneous vertebroplasty, percutaneous kyphoplasty, nerve block, and conservative treatment for nonsurgery options of acute/subacute and chronic osteoporotic vertebral compression fractures (OVCFs) in shortterm and long-term effects. Medicine (Baltimore) 97:e11544. https://doi.org/10.1097/MD.0000000000011544

14. Ontario HQ (2016) Vertebral augmentation involving vertebroplasty or kyphoplasty for cancer-related vertebral compression fractures: an economic analysis. Ont Health Technol Assess Ser 16:1-34

15. De Leacy R, Chandra RV, Barr JD, Brook A, Cianfoni A, Georgy B, Jhamb A, Lohle PNM, Manfre L, Marcia S, Venmans A, Bageac D, Hirsch JA (2020) The evidentiary basis of vertebral augmentation: a 2019 update. J Neurointerv Surg 12:442-447. https://doi.org/10.1136/neurintsurg-2019-015026

16. Richards SJG, Frizelle FA, Geddes JA, Eglinton TW, Hampton MB (2018) Frailty in surgical patients. Int J Color Dis 33:16571666. https://doi.org/10.1007/s00384-018-3163-y

17. Shem Tov L, Matot I (2017) Frailty and anesthesia. Curr Opin Anaesthesiol 30:409-417. https://doi.org/10.1097/ACO.00000 00000000456

18. Manchikanti L, Abdi S, Atluri S, Balog CC, Benyamin RM, Boswell MV, Brown KR, Bruel BM, Bryce DA, Burks PA, 
Burton AW, Calodney AK, Caraway DL, Cash KA, Christo PJ, Damron KS, Datta S, Deer TR, Diwan S et al (2012) American Society of Interventional Pain Physicians (ASIPP) guidelines for responsible opioid prescribing in chronic non-cancer pain: Part 2--guidance. Pain Physician 15:S67-S116

19. Manchikanti L, Abdi S, Atluri S, Balog CC, Benyamin RM, Boswell MV, Brown KR, Bruel BM, Bryce DA, Burks PA, Burton AW, Calodney AK, Caraway DL, Cash KA, Christo PJ, Damron KS, Datta S, Deer TR, Diwan S et al (2012) American Society of Interventional Pain Physicians (ASIPP) guidelines for responsible opioid prescribing in chronic non-cancer pain: Part I--evidence assessment. Pain Physician 15:S1-S65

20. Manchikanti L, Atluri S, Hansen H, Benyamin RM, Falco FJ, Helm Ii S, Kaye AD, Hirsch JA (2014) Opioids in chronic noncancer pain: have we reached a boiling point yet. Pain Physician 17:E1-E10

21. Manchikanti L, Kaye AM, Knezevic NN, McAnally H, Slavin K, Trescot AM, Blank S, Pampati V, Abdi S, Grider JS, Kaye AD, Manchikanti KN, Cordner H, Gharibo CG, Harned ME, Albers SL, Atluri S, Aydin SM, Bakshi S et al (2017) Responsible, Safe, and effective prescription of opioids for chronic noncancer pain: American society of interventional pain physicians (ASIPP) Guidelines. Pain Physician 20:S3-S92

22. Dowell D, Haegerich TM, Chou R (2016) CDC guideline for prescribing opioids for chronic pain--United States, 2016. JAMA 315:1624-1645. https://doi.org/10.1001/jama.2016.1464

23. Hatheway JA, Bansal M, Nichols-Ricker CI (2019) Systemic opioid reduction and discontinuation following implantation of intrathecal drug-delivery systems for chronic pain: a retrospective cohort analysis. Neuromodulation. 10.1111/ner.13053

24. Ali A, Arif AW, Bhan C, Kumar D, Malik MB, Sayyed Z, Akhtar KH, Ahmad MQ (2018) Managing chronic pain in the elderly: an overview of the recent therapeutic advancements. Cureus 10:e3293. https://doi.org/10.7759/cureus.3293

25. Chau DL, Walker V, Pai L, Cho LM (2008) Opiates and elderly: use and side effects. Clin Interv Aging 3:273-278. https://doi.org/ 10.2147/cia.s 1847

26. Kim JY, Kim JH, Yee J, Song SJ, Gwak HS (2018) Risk factors of opioid-induced adverse reactions in elderly male outpatients of Korea Veterans Hospital. BMC Geriatr 18:293. https://doi.org/10. 1186/s12877-018-0990-1

27. Watanabe JH (2016) Medication Use, falls, and fall-related worry in older adults in the United States. Consult Pharm 31:385-393. https://doi.org/10.4140/TCP.n.2016.385

28. Weiner DK, Hanlon JT, Studenski SA (1998) Effects of central nervous system polypharmacy on falls liability in communitydwelling elderly. Gerontology 44:217-221. https://doi.org/10. $1159 / 000022013$

29. Hinde K, Maingard J, Hirsch JA, Phan K, Asadi H, Chandra RV (2020) Mortality outcomes of vertebral augmentation (vertebroplasty and/or balloon kyphoplasty) for osteoporotic vertebral compression fractures: a systematic review and Meta-analysis. Radiology 295:96-103. https://doi.org/10.1148/radiol.2020191294

30. Kern DM, Zhou S, Chavoshi S, Tunceli O, Sostek M, Singer J, LoCasale RJ (2015) Treatment patterns, healthcare utilization, and costs of chronic opioid treatment for non-cancer pain in the United States. Am J Manag Care 21:e222-e234

31. Stearns LJ, Narang S, Albright RE, Hammond K, Xia Y, Richter HB, Paramanandam GK, Haagenson KK, Doth AH (2019) Assessment of health care utilization and cost of targeted drug delivery and conventional medical management vs conventional medical management alone for patients with cancer-related pain. JAMA Netw Open 2:e191549. https://doi.org/10.1001/jamanetworkopen. 2019.1549

32. Charlson ME, Pompei P, Ales KL, MacKenzie CR (1987) A new method of classifying prognostic comorbidity in longitudinal studies: development and validation. J Chronic Dis 40:373-383

33. Clark W, Bird P, Gonski P, Diamond TH, Smerdely P, McNeil HP, Schlaphoff G, Bryant C, Barnes E, Gebski V (2016) Safety and efficacy of vertebroplasty for acute painful osteoporotic fractures (VAPOUR): a multicentre, randomised, double-blind, placebocontrolled trial. Lancet 388:1408-1416. https://doi.org/10.1016/ S0140-6736(16)31341-1

34. Firanescu CE, de Vries J, Lodder P, Venmans A, Schoemaker MC, Smeets AJ, Donga E, Juttmann JR, Klazen CAH, Elgersma OEH, Jansen FH, Tielbeek AV, Boukrab I, Schonenberg K, van Rooij WJJ, Hirsch JA, Lohle PNM (2018) Vertebroplasty versus sham procedure for painful acute osteoporotic vertebral compression fractures (VERTOS IV): randomised sham controlled clinical trial. BMJ 361:k1551. https://doi.org/10.1136/bmj.k1551

35. Boonen S, Van Meirhaeghe J, Bastian L, Cummings SR, Ranstam J, Tillman JB, Eastell R, Talmadge K, Wardlaw D (2011) Balloon kyphoplasty for the treatment of acute vertebral compression fractures: 2-year results from a randomized trial. J Bone Miner Res 26:1627-1637. https://doi.org/10.1002/jbmr.364

36. Dohm M, Black CM, Dacre A, Tillman JB, Fueredi G, KAVIAR I (2014) A randomized trial comparing balloon kyphoplasty and vertebroplasty for vertebral compression fractures due to osteoporosis. Am J Neuroradiol 35:2227-2236. https://doi.org/10.3174/ ajnr.A4127

37. Leslie DL, Ba DM, Agbese E, Xing X, Liu G (2019) The economic burden of the opioid epidemic on states: the case of Medicaid. Am J Manag Care 25:S243-S249

38. American Geriatrics Society Panel on Pharmacological Management of Persistent Pain in Older Persons (2009) Pharmacological management of persistent pain in older persons. J Am Geriatr Soc 57:1331-1346. https://doi.org/10.1111/j.1532-5415.2009.02376.x

39. Rogers E, Mehta S, Shengelia R, Reid MC (2013) Four strategies for managing opioid-induced side effects in older adults. Clin Geriatr 21

40. Papaleontiou M, Henderson CR, Turner BJ, Moore AA, Olkhovskaya Y, Amanfo L, Reid MC (2010) Outcomes associated with opioid use in the treatment of chronic noncancer pain in older adults: a systematic review and meta-analysis. J Am Geriatr Soc 58:1353-1369. https://doi.org/10.1111/j.1532-5415.2010.02920.x

Publisher's note Springer Nature remains neutral with regard to jurisdictional claims in published maps and institutional affiliations. 